\title{
Quantitation of the Total Catechin Content in Oils Extracted from Seeds of Selected Tea (Camellia sinensis (L) 0. Kuntze, Theaceae) Clones by RP-HPLC
}

\author{
Kelvin Omondi George1,2, Kelvin Okong'o Moseti ${ }^{2,3^{*}}$, John Kanyiri Wanyoko ${ }^{3}$, \\ Thomas Kinyanjui' ${ }^{2}$, Francis Nyamu Wachira ${ }^{4}$ \\ ${ }^{1}$ Nairobi Bottlers Limited, Nairobi, Kenya \\ ${ }^{2}$ Chemistry Department, Egerton University, Nakuru, Kenya \\ ${ }^{3}$ Tea Research Institute, Kericho, Kenya \\ ${ }^{4}$ Association for Strengthening Agricultural Research in Eastern and Central Africa, Entebbe, Uganda \\ Email: ${ }^{*}$ kelvinmoseti@gmail.com, kmoseti@tearesearch.or.ke
}

Received 19 February 2015; accepted 27 April 2015; published 30 April 2015

Copyright $(2015$ by authors and Scientific Research Publishing Inc.

This work is licensed under the Creative Commons Attribution International License (CC BY).

http://creativecommons.org/licenses/by/4.0/

\section{(c) (i) Open Access}

\section{Abstract}

Catechins (flavan-3-ols) are polyphenolic plant secondary metabolites that have been strongly associated with a wide variety of beneficial health effects in vitro, in vivo and clinically. This study reports findings on the content of catechins in tea seed oil (TSO) extracted by Soxhlet extraction from seeds of different clones of Kenyan tea. Extraction of catechins from the crude oils was achieved by sequential liquid-liquid extraction (LLE) using methanol and quantified by reverse phase High Performance Liquid Chromatography (RP-HPLC). Results obtained revealed that all the crude test oils contained catechins, with oils extracted from clones TRFK K-Purple and GW-Ejulu having the highest total catechin content of $9.8 \pm 0.25$ and $9.0 \pm 0.83\left(\times 10^{-3} \%\right.$ flavonoids $)$ respectively. Statistically significant differences $(p<0.05)$ were evident in the total catechin contents of crude oils extracted from tea seeds with those extracted from corn, sunflower and soybean seeds. Moreover, clonal variations were evident, as the total catechin contents of oils extracted from clones TRFK K-Purple and GW-Ejulu were statistically different $(p<0.05)$ from those extracted from clones TRFK 301/3, TRFK 301/4, TRFK 301/5, TRFK 306, TRFK 91/1 and TRFCA SFS 150. Thus, the current findings strongly suggest that oils from seeds of Kenyan tea cultivars can be a potential source of potent natural antioxidants.

\footnotetext{
"Corresponding author.
} 


\section{Keywords}

\section{Soxhlet Extraction, TSO, RP-HPLC, Catechins, LLE}

\section{Introduction}

The tea plant is mainly cultivated for its prolific vegetative growth [1] from which different types of tea products have been processed viz., white [2] green [3], oolong and black tea [4]-[6]. However, the tea plant also produces seeds from which high quality tea seed oil (TSO) can be pressed or extracted using suitable solvent(s) or solvent systems [6]-[8] with tea seed cake and husks as by-products. The physico-chemical properties of the above byproducts have also been investigated and reported [9]-[11]. Further, various studies have reported a wide range of findings on extracts of flowers and stem barks of the tea plant, though to a less extent [12]-[14].

Tea is widely consumed worldwide [15] [16] owing to its medicinal [17], refreshing and mild stimulant effects [18]. Several health benefits have been ascribed to regular tea consumption with many research reports linking such benefits to tea phenolic compounds, mainly catechins [15] [16]. Such health benefits include the reduction of serum cholesterol levels, the lowering of the risks of cancers and cardiovascular diseases [19]-[22] [22], the ability to protect body cells from oxidative stress owing to its potent antioxidant activity [19] [23] [24], amelioration of inflammation [25], controlling of diabetes [26]-[30], antifungal properties [31], antimicrobial, and antibacterial activities [24] [32]-[34], among many more.

Seeds of different plants usually contain various antioxidants. Indeed, it has recently been reported that the naturally occurring active compounds in tea seeds are different from those in other kinds of oil seeds as is the case of saponin [35]. Catechins are amongst a group of polyphenols that have been reported to be present in TSO in different proportions [36]. It has been reported that the extraction of polyphenols from plant oils has been achieved in the past using different solvents employing various techniques which include liquid-liquid extraction [37]. Quantitation of the polyphenolic content of such oils has been achieved using various methods among them volumetric titrations and colorimetric measurements. Polyphenol levels in TSO have been reported before [38] as well as the antioxidant activity and bioactive compounds studies of TSO [6] [8] [39]. Moreover, [36] documents the presence of antioxidants in TSO and concludes that catechins can be amongst the compounds responsible for the antioxidant activity of TSO. [39] reports that sesamin and 2,5-bis-benzo [1] [3] dioxol-5-yl-tetrahydro-furo [3,4- $d][1,3]$-dioxine have been isolated in TSO extracted from Camellia oleifera Abel, and attributes the oils' antioxidant activity to the presence of these two compounds.

Kenya has continued to be a producer of processed tea at the primary level with very little product differentiation and value addition, over $95 \%$ of which is sold in bulk in the export market. Owing to global overproduction of tea, the profitability of the Kenyan tea enterprise has declined in the recent past. Thus, the need to diversify tea products in a bid to reshape the future of this key industry cannot be understated. Indeed, the need for researchers and tea industry stakeholders in Kenya to exploit TSO as an avenue to ease on the current dwindling returns to tea farmers resulting from global overproduction of black tea is the need of the day. With this in mind, the current research seeks to quantify the total catechin content in TSO extracted from seeds of selected Kenyan tea clones, with the expectation that findings from the research will immensely contribute to the development of diversified products from the tea plant, hence enhancing sustainability and profitability of the local tea industry.

\section{Materials and Methods}

\subsection{Reference Compounds and Reagents}

Authentic catechin standards viz., (+)-catechin (C), (-)-epicatechin (EC), epigallocatechin (EGC), (-)-epicatechingallate (ECG) and (-)-epigallocatechingallate (EGCG) were purchased from Sigma Aldrich, Germany. Also, the following chemicals were used; $n$-hexane ( $\geq 99.5 \%)$, methanol $(\geq 99.5 \%)$, ethylenediaminetetraacetic acid (EDTA $\geq 99.1 \%$ ), acetonitrile (HPLC grade), ascorbic acid ( $\geq 99.0 \%$ ) and nitrogen gas $(99.9 \%)$. Double distilled water was used in all dilutions throughout the study.

\subsection{Tea Seeds and Control Samples}

Mature and healthy tea seeds from eight randomly selected clones of tea viz., TRFK 301/3, TRFK 301/4, TRFK 301/5, GW-Ejulu, K-Purple, TRFK 306, TRFK 91/1 and TRFCA SFS 150, were harvested in triplicates from 
mature, healthy tea plants (Figure 1(a) and Figure 1(b)) from Timbilil Estate seed barie of the Tea Research Institute (TRI), Kericho, Kenya. Each replicate for each clone studied was obtained from a different tea plant. Further, maize germ, sunflower seeds and soybean seeds, were obtained in triplicates from Bidco Oil Refineries Ltd., Elianto Division, Nakuru, Kenya for use as controls.

\subsection{Soxhlet Extraction of TSO}

Sun-dried tea seeds were manually de-husked and the husks carefully separated from the kernels (Figure 2(a) and Figure 2(b)). The desired tea seed kernels were finely milled using an electric kitchen blender (Philips HL7510/00, Netherlands), for size reduction and sample homogenization. The powdered samples were then oven-dried at $80^{\circ} \mathrm{C} \pm 2{ }^{\circ} \mathrm{C}$ for 12 hours and kept in well dessicated dessicators until use. Solvent extraction was carried out using a simple laboratory set up of a standard soxhlet apparatus employing $n$-hexane as the solvent

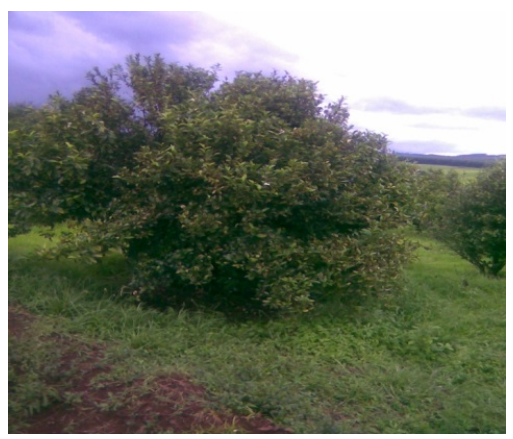

(a)

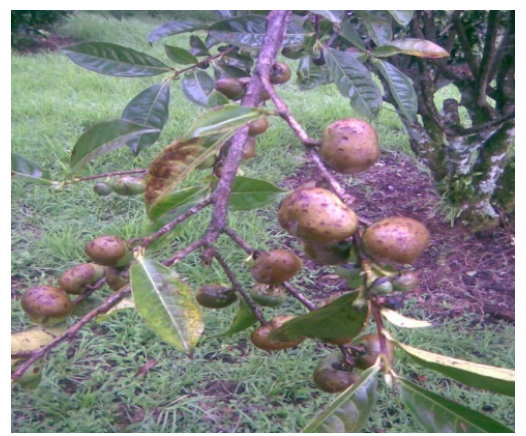

(b)

Figure 1. (a) A fully grown tea plant at the seed barie of the Tea Research Institute (TRI), Kericho, Kenya; (b) A branch of the tea plant with mature tea seeds.

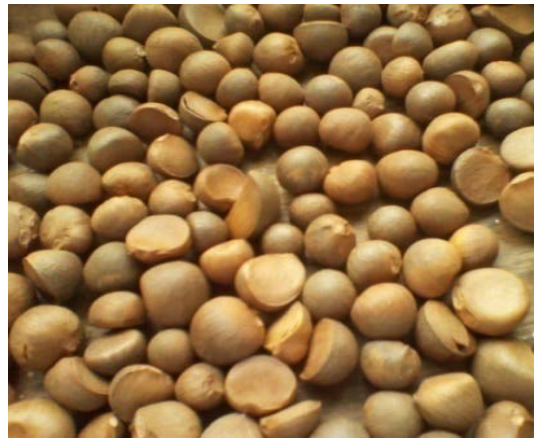

(a)

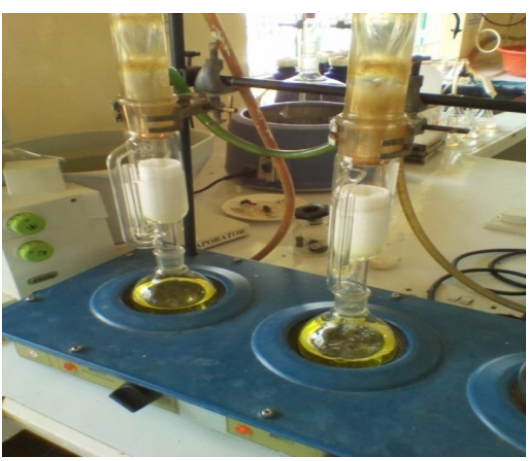

(c)

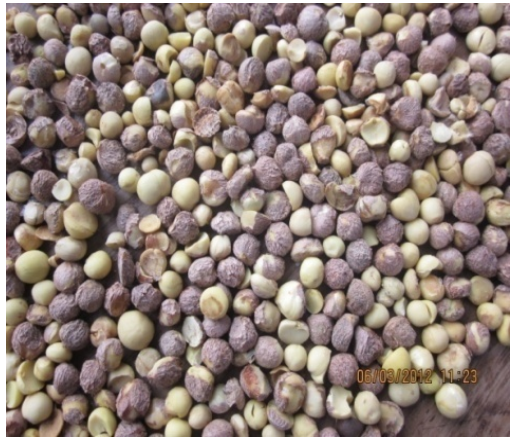

(b)

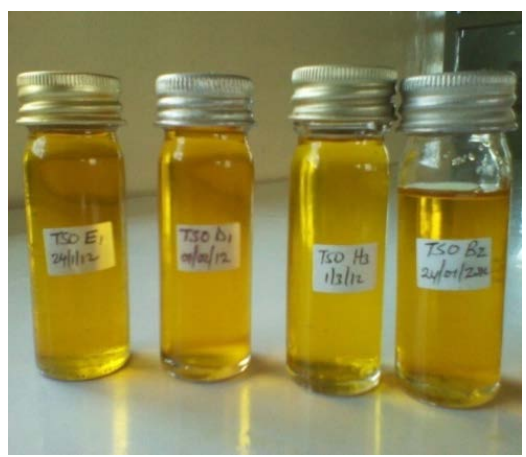

(d)

Figure 2. (a) Mature sun-dried tea seeds; (b) De-husked tea seeds; (c) A portion of the series of soxhlet apparatus used in the extraction of the crude oils; (d) Crude oils in well labeled airtight sample bottles. 
(Figure 2(c)). The sample to solvent ratio employed was 1:20 and the extraction was done for 8 hours. The $n$-hexane extract was concentrated by rotary evaporation at $60^{\circ} \mathrm{C} \pm 0.5^{\circ} \mathrm{C}$ using a rotary evaporator (Model $\mathrm{R}-3000$, Buchi, Switzerland) and then placed in an oven at $80^{\circ} \mathrm{C} \pm 2{ }^{\circ} \mathrm{C}$ for an hour to evaporate any residual solvent after which it was transferred into well labeled sample bottles (Figure 2(d)). A stream of nitrogen gas was blown into the head space of the sample bottles containing the crude TSO extracts, tightly closed and kept refrigerated at $-15^{\circ} \mathrm{C} \pm 0.5^{\circ} \mathrm{C}$ awaiting analysis. This was repeated for all the replicates of all the tea seed and control samples.

\subsection{Extraction of Catechins}

Extraction of catechins from the crude oils was achieved by dissolving $2.0 \pm 0.001 \mathrm{~g}$ of oil in $2.0 \mathrm{~mL}$ of $n$-hexane in $10 \mathrm{~mL}$ graduated extraction tubes. The mixture was thoroughly mixed using a vortex mixer (VM-1000, Digisystem Laboratory Instruments Inc., Taiwan) for one minute followed by liquid-liquid extraction (LLE) using $4.0 \mathrm{~mL}$ of 80:20 v/v methanol: water mixture in order to assay the polar fraction. The final mixture was vortexed for 10 seconds followed by centrifugation for 10 minutes at 3500 revolutions per minute (rpm), using a digital high speed universal centrifuge (HSCEN-204, M.R.C Ltd., Israel) fitted with a rotor (RA-1512S, M.R.C Ltd., Israel). The supernatant (methanolic extract) was decanted into a clean graduated tube and the same sample was subjected to a second and third extractions only with the addition of $4.0 \mathrm{~mL}$ of the $80: 20 \mathrm{v} / \mathrm{v} \mathrm{me-}$ thanol:water mixture; each time, the supernatant was collected in the same graduated tube for each replicate of each sample. The methanolic extracts were stored refrigerated at $-15^{\circ} \mathrm{C} \pm 0.5^{\circ} \mathrm{C}$ until the time of analysis.

\subsection{Chromatographic Determination of Catechins}

The catechins content in the methanolic extracts of the crude oils were quantitatively estimated by Reverse Phase High Performance Liquid Chromatography (RP-HPLC). $1.0 \mathrm{~mL}$ of the methanolic extract was accurately transferred into a clean and dry graduated sample tube and diluted to $5.0 \mathrm{~mL}$ with a stabilizing solution constituting of $10 \% \mathrm{v} / \mathrm{v}$ acetonitrile, $500 \mu \mathrm{g} \cdot \mathrm{mL}^{-1}$ ethylenediaminetetraacetic acid (EDTA) and $10 \mathrm{mg} \cdot \mathrm{mL}^{-1}$ ascorbic acid in the ratio $2: 1: 1$, diluted five times. The solution was then filtered through a $0.45 \mu \mathrm{m}$ nylon membrane filter and transferred into sample vials. The chromatographic set-up comprised of a Shimadzu LC 20 AT HPLC system fitted with a SIL 20A auto-sampler, an SPD-20 UV-Visible detector, a class LC10 chromatography workstation and a Gemini $5 \mu \mathrm{m} \mathrm{C}_{6}$ Phenyl $110 \AA, 250 \mathrm{~mm} \times 4.6 \mathrm{~mm}$ i.d (Phenomenex, Torrance, CA, USA) separation column.

A binary gradient elution was carried out using two solvent systems, eluents $\mathrm{A}$ and $\mathrm{B}$, constituting of acetonitrile/acetic acid/double distilled water in the ratios 9:2:89 and 80:2:18 v/v/v respectively. The eluent composition for the binary gradient condition started at 100\% eluent A for 10 minutes, then over 15 minutes, a linear gradient to $68 \%$ eluent A, $32 \%$ eluent B and held at this composition for 7 minutes. The condition was then reset to $100 \%$ eluent $\mathrm{A}$ and allowed to equilibrate for 10 minutes before the next injection. The flow rate of the eluents, injection volume, column temperature and $\lambda_{\max }$ were $1.0 \mu \mathrm{L} \cdot \mathrm{min}^{-1}, 20 \mu \mathrm{L}, 35^{\circ} \mathrm{C} \pm 0.5^{\circ} \mathrm{C}$ and $278 \mathrm{~nm}$, respectively. Identification of individual catechins was carried out by comparing the retention times of the sample peaks with those of the authentic catechin standards and caffeine analysed under similar conditions. Quantitation of catechins and caffeine were performed using the caffeine calibration curve obtained (Figure 3) in conjunction with the consensus individual catechin relative response factors (RRFs) with respect to caffeine on a dry matter basis. The total catechin content as percentage by mass was given by the summation of individual catechin contents, that is, $\% \mathrm{ECG}+\% \mathrm{EGC}+\% \mathrm{EC}+\% \mathrm{EGCG}+\% \mathrm{C}$.

\subsection{Data Analysis}

Data obtained were subjected to analysis of variance (ANOVA) using MSTAT statistical package version 2.10 at $\mathrm{p}<0.05$. The least significant difference (LSD) test was used in mean separation where statistically significant differences were recorded. Data are tabulated as means of the triplicate determinations \pm standard deviation.

\section{Results and Discussion}

The caffeine calibration curve obtained $(y=50617 x+473.6)$ and used in the quantitation of the individual ca- 


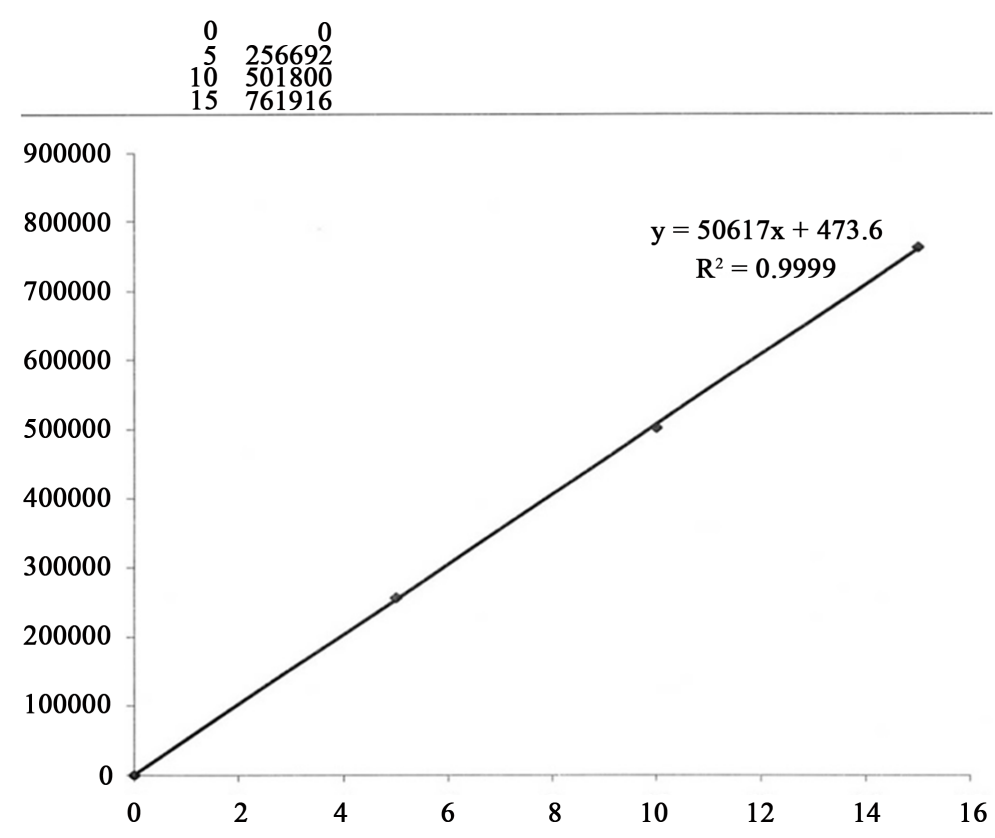

Figure 3. Calibration curve of the caffeine reference standard.

techin contents in the methanolic extracts of the crude oils demonstrated adequate linearity, $\mathrm{r}^{2}=0.9999$ (Figure $3)$. The major catechins that are normally present in the both green and purple leaf coloured tea (Camellia sinensis) plants were also present in all the test oils viz., (-)-epigallocatechin (EGC), (+)-catechin (C), (-)-epicatechin (EC), (-)-epigallocatechin gallate (EGCG) and (-)-epicatechin gallate (EGC) [40]-[47]. However, the levels reported in the oils studied were much lower than those reported in tea leaves. Plant polyphenols are mainly found in fruit skins and seeds and as such, their levels after analysis may reflect only the measured extractable polyphenols content of a fruit which may also contain non-extractable polyphenols [48]. This could be a possible explanation of the low levels of catechins extracted and quantified in this research work.

The order of elution of the catechins was EGC, + C, EC, EGCG and ECG. Figure 4 is a representative HPLC chromatogram of the catechin content in crude oil extracted from seeds of clone TRFK 91/1, whereas Figure 5 is an auto-scaled representation of the HPLC chromatogram in Figure 4 (X-axis auto-scaled to between 5 and 30 minutes and the Y-axis auto-scaled to the second largest peak) to help visualize the diminished peaks resulting from the low levels of catechins extracted from the crude oils. The simple non-gallated catechins, (-)-EGC, $(+)-\mathrm{C}$ and (-)-EC, were eluted first whereas the gallated catechins, (-)-EGCG and (-)-ECG, were eluted last. This is because the non-gallated catechins are polar and bind tightly to the non-polar $\mathrm{C}_{6}$ column and are eluted first upon introduction of a highly polar mobile phase $\mathrm{A}$ whereas the gallated catechins are eluted last since they bind more tightly to the column and are eluted upon increase of the mobile phase B which makes the mobile phase composition less polar, explaining the order of elution.

The total catechin contents of the crude tea and control oils were as given in Table 1. Oils extracted from clone TRFK K-Purple and GW-Ejulu had the highest total catechin content of $9.8 \pm 0.25$ and $9.0 \pm 0.83\left(\times 10^{-3} \%\right.$ flavonoids), respectively. On the other hand, crude oils extracted from the maize germ (corn), sunflower and soybean used as controls in the current experiment recorded the lowest total catechin contents of $1.9 \pm 0.21,0.7$ \pm 0.24 and $1.6 \pm 0.66\left(\times 10^{-3} \%\right.$ flavonoids $)$ respectively. Analysis of variance showed statistically significant differences $(p<0.05)$ in the total catechin content of crude oils extracted from tea seeds with those extracted from the three controls (Table 1). Clonal variations were also evident, since the total catechin contents of oils extracted from clones TRFK K-Purple and GW-Ejulu were statistically different $(\mathrm{p}<0.05)$ from those extracted from clones TRFK 301/3, TRFK 301/4, TRFK 301/5, TRFK 306, TRFK 91/1 and TRFCA SFS 150.

Reference [36] report the concentration of phenolic compounds in TSO to be $24.81 \pm 1.0 \mathrm{mg} \cdot \mathrm{kg}^{-1}$, the major component being identified to be (-)-EGCG with a concentration of $12.93 \pm 1.0 \mathrm{mg} \cdot \mathrm{kg}^{-1}$. They further argue that although tocopherols and carotenoids can be found in other vegetable oils, phenolic compounds are found only in TSO and can as such be concluded that the main antioxidant activities of TSO are due to phenolic and toco- 


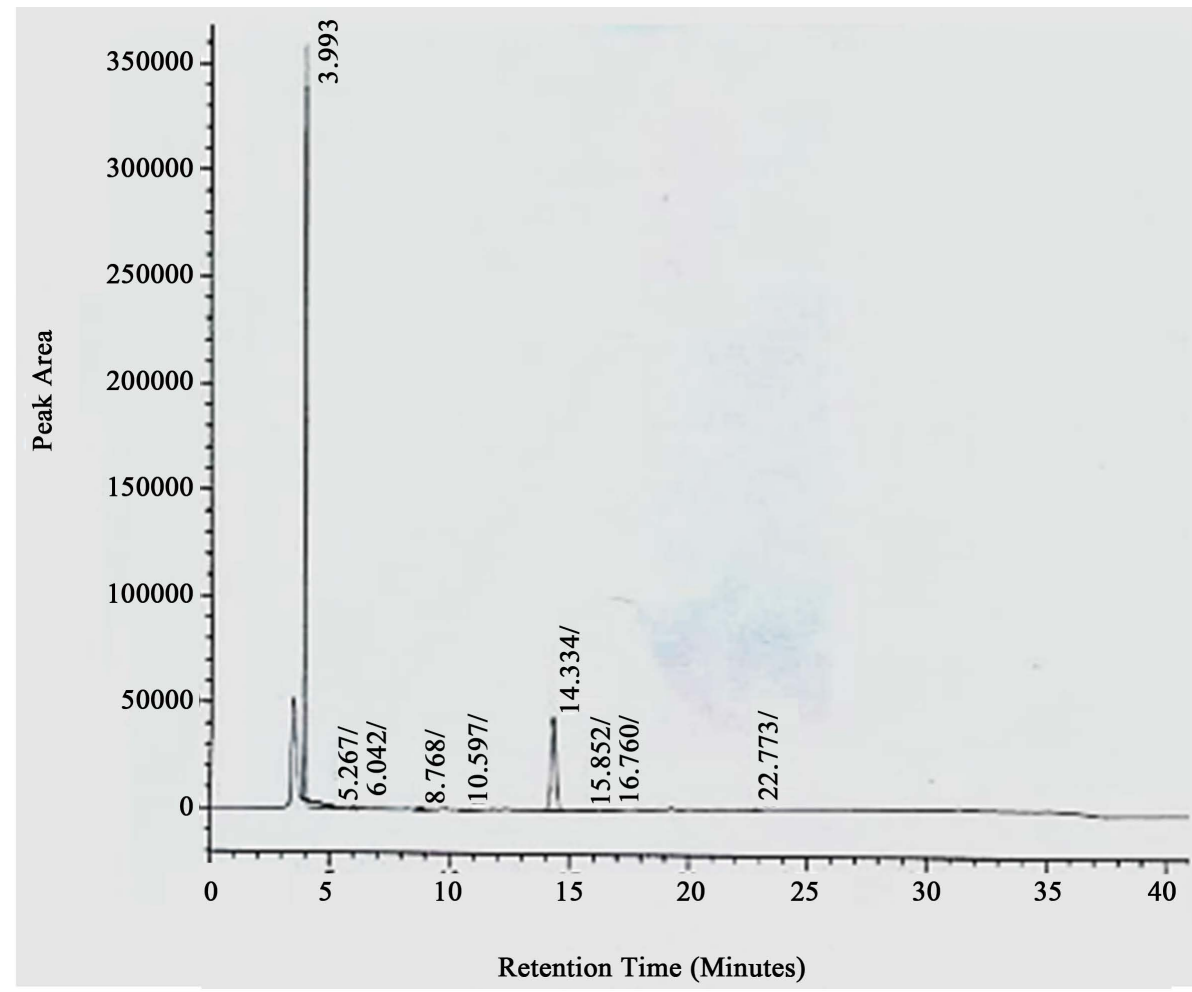

Figure 4. HPLC chromatogram of the catechin content in crude oil extracted from seeds of clone TRFK 91/1.

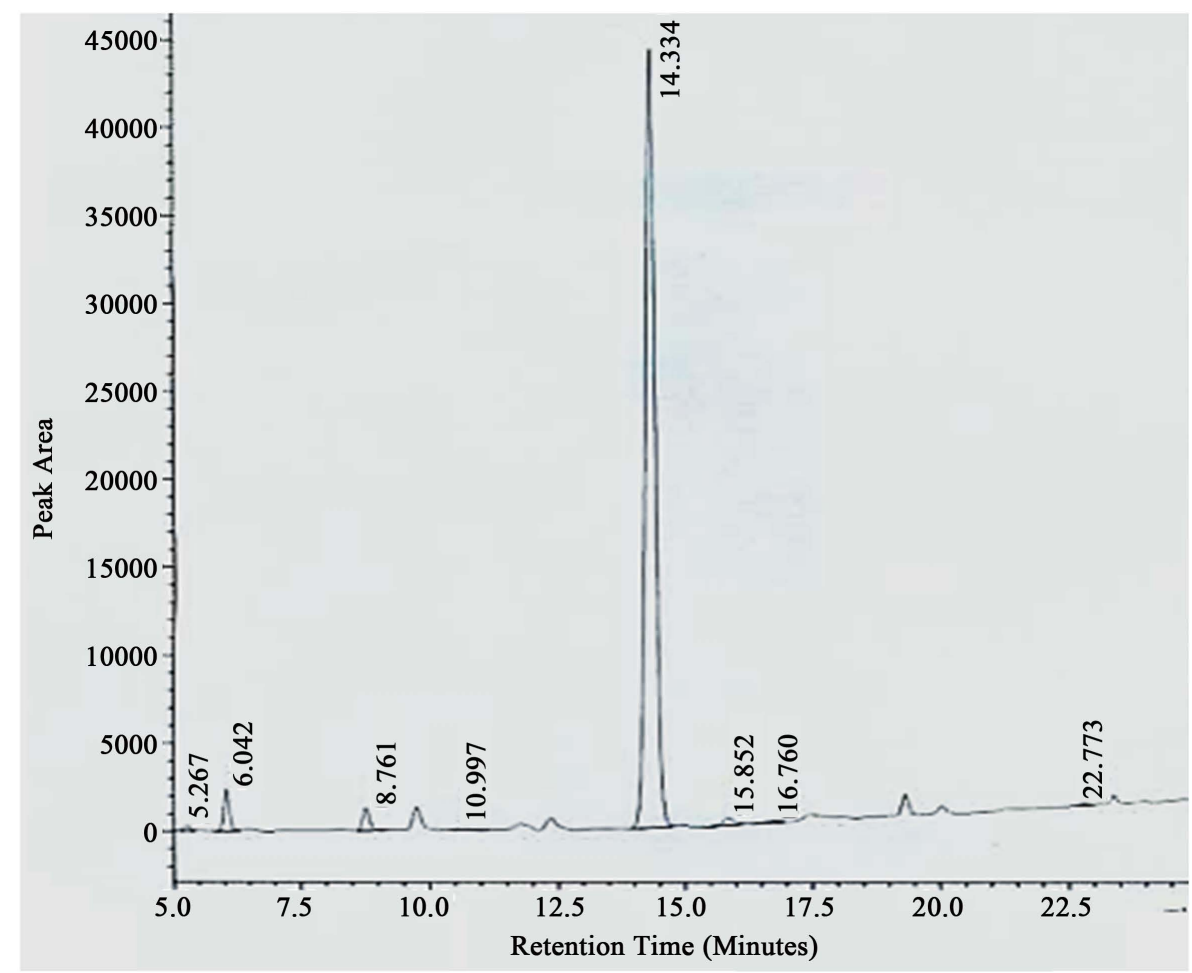

Figure 5. The HPLC chromatogram of the catechin content in crude oil extracted from seeds of clone TRFK 91/1 (Figure 4) with the X-axis auto-scaled to between 5 and 30 minutes and the $\mathrm{Y}$-axis auto-scaled to the second largest peak. 
Table 1. Total catechin content in the crude oils expressed as $\%$ flavonoids.

\begin{tabular}{cc}
\hline Tea clone & Total catechin content $\left(\times \mathbf{1 0}^{-3}\right)$ \\
\hline TRFK 301/3 & ${ }^{\circ b} 6.4 \pm 0.34$ \\
TRFK 301/4 & ${ }^{\mathrm{b}} 4.8 \pm 1.09$ \\
TRFK 301/5 & ${ }^{\mathrm{b}} 4.9 \pm 0.41$ \\
GW-Ejulu & ${ }^{\mathrm{a}} 9.0 \pm 0.83$ \\
TRFK K-Purple & ${ }^{\mathrm{a}} 9.8 \pm 0.25$ \\
TRFK 306 & ${ }^{\mathrm{b}} 5.9 \pm 1.70$ \\
TRFK 91/1 & ${ }^{\mathrm{b}} 5.0 \pm 1.11$ \\
TRFCA SFS 150 & ${ }^{\mathrm{b}} 5.1 \pm 0.48$ \\
${ }^{*}$ Corn & ${ }^{\mathrm{c}} 1.9 \pm 0.21$ \\
*Sunflower & ${ }^{\mathrm{c}} 0.7 \pm 0.24$ \\
${ }^{*}$ Soybean & ${ }^{\mathrm{c}} 1.6 \pm 0.66$ \\
Overall mean & $\mathbf{5 . 0 1}$ \\
CV (\%) & 19.1 \\
LSD & 1.6 \\
\hline
\end{tabular}

"Samples used as controls; CV: coefficient of variation; LSD: Least Significant Difference; \#Values preceded with the same superscript letter are not statistically different at $(\mathrm{p} \leq 0.05)$.

pherol compounds. However, the current data also demonstrates the presence of catechins in the three vegetable oils (corn, soybean and sunflower) used as controls. Earlier, the current authors reported that TSO from clone GW- Ejulu had the highest total polyphenolic content $\left(0.043 \mathrm{mg} \cdot \mathrm{L}^{-1}\right.$ gallic acid $)$ as well as antioxidant capacity (20.6\% 2,2-diphenyl-1-picrylhydrazyl, DPPH, radical scavenging activity [6]. The difference in catechins levels from this study compared to other TSO's reported before could be due to clonal variations, differences in geographical and climatic conditions. The method used in the extraction of the polyphenols from the TSO could also partially contribute to the differences. It has also been shown before that the method employed in the extraction of oil from seeds and the type of solvent used to some extent have notable effects on the appearance and quality of the extracted oil [49]-[52].

Prior to the reports by [6] and [9]-[11], the only other attempt to study the physical and chemical properties of TSO and its by-products with a view of harnessing the same for potential use as a functional product with various technical applications was by [53]. Indeed the current findings expose a gap that can potentially benefit farmers, especially those in marginal areas, where tea growing for the purposes of leave production is not economically sustainable.

\section{Conclusion}

Findings of this study clearly demonstrate the presence of catechins in all crude oils extracted from the tea seeds obtained from eight clones of Kenyan tea. These polyphenolic compounds have been reported to possess potent antioxidant activity thought to account for their protective role against a number of diseases. Thus, TSO is a promising source of natural antioxidants, as well as a potential source of diversified products from the tea plant and extra income for tea growers.

\section{Conflict of Interest}

The authors confirm that this article content has no conflict of interest. 


\section{Acknowledgements}

The authors acknowledge the Tea Research Institute (TRI) formerly the Tea Research Foundation of Kenya (TRFK) for funding this project. This article is published with the permission of the director, TRI.

\section{References}

[1] Sahari, M. and Amooi, M. (2013) Tea Seed Oil: Extraction, Compositions, Applications, Functional and Antioxidant Properties. Academia Journal of Medicinal Plants, 1, 68-79.

[2] Hilal, Y. and Engelhardt, U. (2007) Characterisation of White Tea-Comparison to Green and Black Tea. Journal of Consumer Protection and Food Safety, 2, 414-421.

[3] Rusak, G., Komes, D., Likić, S., Horžić, D. and Kovač, M. (2008) Phenolic Content and Antioxidative Capacity of Green and White Tea Extracts Depending on Extraction Conditions and the Solvent Used. Food Chemistry, 110, 852858. http://dx.doi.org/10.1016/j.foodchem.2008.02.072

[4] Sang, S., Lambert, J.D., Ho, C.T. and Yang, C.S. (2011) The Chemistry and Biotransformation of Tea Constituents. Pharmacological Research, 64, 87-99. http://dx.doi.org/10.1016/j.phrs.2011.02.007

[5] Coe, S., Fraser, A. and Ryan, L. (2013) Polyphenol Bioaccessibility and Sugar Reducing Capacity of Black, Green, and White Teas. International Journal of Food Science, 2013, Article ID: 238216.

[6] George, K.O., Kinyanjui, T., Wanyoko, J., Moseti, O.K. and Wachira, F. (2013) Extraction and Analysis of Tea (Camellia sinensis) Seed Oil from Different Clones in Kenya. African Journal of Biotechnology, 12, 841-846.

[7] Yahaya, L.E., Adebowale, K.O., Olu-Owolabi, B.I. and Menon, A.R.R. (2011) Compositional Analysis of Tea (Camellia sinensis) Seed Oil and Its Application. International Journal of Research in Chemistry and Environment, 1, 153158.

[8] Wang, Y., Sun, D., Chen, H., Qian, L. and Xu, P. (2011) Fatty Acid Composition and Antioxidant Activity of Tea (Camellia sinensis L.) Seed Oil Extracted by Optimized Supercritical Carbon Dioxide. International Journal of Molecular Science, 12, 7708-7719. http://dx.doi.org/10.3390/ijms12117708

[9] Njuguna, D.G., Wanyoko, J.K., Kinyanjui, T. and Wachira, F.N. (2013) Mineral Elements in the Kenyan Tea Seed Oil Cake. International Journal of Research in Chemistry and Environment, 3, 253-261.

[10] Njuguna, D.G., Wanyoko, J.K., Kinyanjui, T. and Wachira, F.N. (2013) Polyphenols and Free Radical Scavenging Properties of Kenyan Tea Seed Oil Cake. International Journal of Research in Chemistry and Environment, 3, 86-92.

[11] Njuguna, D.G., Wanyoko, J.K., Kinyanjui, T. and Wachira, F.N. (2013) Fatty Acids Residues Composition in the De-Oiled Tea Seed Oil Cakes. Science Journal of Biotechnology, 2014, Article ID: sjbt-263.

[12] Yang, Z., Xu, Y., Jie, G., He, P. and Tu, Y. (2007) Study on the Antioxidant Activity of Tea Flowers (Camellia sinensis). Asia Pacific Journal of Clinical Nutrition, 16, 148-152.

[13] Chen, B.T., Li, W.X., He, R.R., Li, Y.F., Tsoi, B., Zhai, Y.J. and Kurihara, H. (2012) Anti-Inflammatory Effects of a Polyphenols-Rich Extract from Tea (Camellia sinensis) Flowers in Acute and Chronic Mice Models. Oxidative Medicine and Cellular Longevity, 2012, Article ID: 537923. http://dx.doi.org/10.1155/2012/537923

[14] Zhang, X., Gao, Y., Xu, J., Liu, X., Jin, F., Li, B. and Tu, Y. (2014) Inhibitory Effect of Tea (Camellia sinensis (L.) O. Kuntze, Theaceae) Flower Extracts on Oleic Acid-Induced Hepatic Steatosis in Hepg2 Cells. Journal of Food and Nutrition Research, 2,738-743. http://dx.doi.org/10.12691/jfnr-2-10-13

[15] Vuong, Q.V. (2014) Epidemiological Evidence Linking Tea Consumption to Human Health: A Review. Critical Reviews in Food Science and Nutrition, 54, 523-536. http://dx.doi.org/10.1080/10408398.2011.594184

[16] Khan, N. and Mukhtar, H. (2007) Tea Polyphenols for Health Promotion. Life Sciences, 81, 519-533. http://dx.doi.org/10.1016/j.lfs.2007.06.011

[17] Singh, V., Verma, D.K. and Singh, G. (2014) Processing Technology and Health Benefits of Green Tea. Popular Kheti, 2, 23-30.

[18] Karak, T. and Bhagat, R.M. (2010) Trace Elements in Tea Leaves, Made Tea and Tea Infusion: A Review. Food Research International, 43, 2234-2252. http://dx.doi.org/10.1016/j.foodres.2010.08.010

[19] Zuo, Y., Chen, H. and Deng, Y. (2002) Simultaneous Determination of Catechins, Caffeine and Gallic Acids in Green, Oolong, Black and Pu-Erh Teas Using HPLC with a Photodiode Array Detector. Talanta, 57, 307-316. http://dx.doi.org/10.1016/S0039-9140(02)00030-9

[20] Chung, F., Schwrtz, J., Herzog, C.R. and Yang, Y. (2003) Tea and Cancer Prevention: Studies in Animals and Humans. Journal of Nutrition, 133, 3268S-3274S.

[21] Yang, C.S., Ju, J., Lu, G., Xiao, H., Hao, X., Sang, S. and Lambert, J.D. (2008) Cancer Prevention by Tea and Tea Po- 
lyphenols. Asia Pacific Journal of Clinical Nutrition, 17, 245-248.

[22] Yang, C.S., Lambert, J.D., Ju, J., Lu, G. and Sang, S. (2007) Tea and Cancer Prevention: Molecular Mechanisms and Human Relevance. Toxicology and Applied Pharmacology, 224, 265-273. http://dx.doi.org/10.1016/j.taap.2006.11.024

[23] Karori, S.M., Wachira, F.N., Wanyoko, J.K. and Ngure, R.M. (2007) Antioxidant Capacity of Different Types of Tea Products. African Journal of Biotechnology, 6, 2287-2296.

[24] Koech, R.K., Wanyoko, J. and Wachira, F. (2014) Antioxidant, Antimicrobial and Synergistic Activities of Tea Polyphenols. International Journal of Infectious Diseases, 21, 98. http://dx.doi.org/10.1016/j.ijid.2014.03.631

[25] Karori, S.M., Ngure, R.M., Wachira, F.N., Wanyoko, J.K. and Mwangi, J.N. (2008) Different Types of Tea Products Attenuate Inflammation Induced in Trypanosoma brucei Infected Mice. Parasitology International, 57, 325-333. http://dx.doi.org/10.1016/j.parint.2008.02.003

[26] Al-Attar, A.M. and Zari, T.A. (2010) Influences of Crude Extract of Tea Leaves, Camellia sinensis, on Streptozotocin Diabetic Male Albino Mice. Saudi Journal of Biological Sciences, 17, 295-301. http://dx.doi.org/10.1016/j.sjbs.2010.05.007

[27] Elshater, A.A., Salman, M.A. and Moussa, M.M.A. (2008) Effect of Green Tea Consumption on Level of Glucose, Lipid Profile and Kidney Functions in Alloxan Induced-Diabetic Rats. Egyptian Academic Journal of Biological Sciences, 1, 125-134.

[28] Tsuneki, H., Ishizuka, M., Terasawa, M., Wu, J.B., Sasaoka, T. and Kimura, I. (2004) Effect of Green Tea on Blood Glucose Levels and Serum Proteomic Patterns in Diabetic (db/db) Mice and on Glucose Metabolism in Healthy Humans. BMC Pharmacology, 4, 18. http://dx.doi.org/10.1186/1471-2210-4-18

[29] Odegaard, A.O., Pereira, M.A., Koh, W.P., Arakawa, K., Lee, H.P. and Yu, M.C. (2008) Coffee, Tea, and Incident Type 2 Diabetes: The Singapore Chinese Health Study. American Journal of Clinical Nutrition, 88, 979-985.

[30] Jing, Y., Han, G., Hu, Y., Bi, Y., Li, L. and Zhu, D. (2009) Tea Consumption and Risk of Type 2 Diabetes: A MetaAnalysis of Cohort Studies. Journal of General Internal Medicine, 24, 557-562. http://dx.doi.org/10.1007/s11606-009-0929-5

[31] Koech, K.R., Wachira, F.N., Ngure, R.M., Orina, I.A., Wanyoko, J.K., Bii, C. and Karori, S.M. (2013) Antifungal Activity of Crude Tea Extracts. African Journal of Agricultural Research, 8, 2086-2089.

[32] Koech, K.R., Wachira, F.N., Ngure, R.M., Wanyoko, J.K., Bii, C. and Karori, S.M. (2013) Antibacterial and Synergistic Activity of Different Tea Crude Extracts Against Antibiotic Resistant S. aureus, E. coli and a Clinical Isolate of $S$. typhi. Science Journal of Microbiology, 2013, Article ID: sjmb-115.

[33] Mbuthia, S.K., Wachira, F.N. and Koech, R.K. (2014) In Vitro Antimicrobial and Synergistic Properties of Water Soluble Green and Black Tea Extracts. African Journal of Microbiology Research, 8, 1527-1534. http://dx.doi.org/10.5897/AJMR2014.6655

[34] Koech, K.R., Wachira, F.N., Ngure, R.M., Wanyoko, J.K., Bii, C.C., Karori, S.M. and Kerio, L.C. (2013) Antimicrobial, Synergistic and Antioxidant Activities of Tea Polyphenols. In: Méndez-Vilas, A., Ed., Microbial Pathogens and Strategies for Combating Them: Science, Technology and Education, Formatex Research Center, Badajoz, 971-981.

[35] Li, H., Zhou, G.Y., Zhang, H.Y. and Liu, J.A. (2011) Research Progress on the Health Function of Tea Oil. Journal of Medicinal Plants Research, 5, 485-489.

[36] Fazel, M., Sahari, M.A. and Barzegar, M. (2008) Determination of Main Tea Seed Oil Antioxidants and Their Effects on Common Kilka Oil. International Food Research Journal, 15, 209-217.

[37] Pan, X., Niu, G. and Liu, H. (2003) Microwave-Assisted Extraction of Tea Polyphenols and Tea Caffeine from Green Tea Leaves. Chemical Engineering and Processing, 42, 129-133. http://dx.doi.org/10.1016/S0255-2701(02)00037-5

[38] Zhang, L., Wang, Y., Wu, D., Xu, M. and Chen, J. (2011) Microwave-Assisted Extraction of Polyphenols from Camellia oleifera Fruit Hull. Molecules, 16, 4428-4437. http://dx.doi.org/10.3390/molecules16064428

[39] Lee, C.P. and Yen, G.C. (2006) Antioxidant Activity and Bioactive Compounds of Tea Seed (Camellia oleifera Abel.) Oil. Journal of Agricultural and Food Chemistry, 54, 779-784. http://dx.doi.org/10.1021/jf052325a

[40] Cherotich, L., Kamunya, S.M., Alakonya, A., Msomba, S.W., Uwimana, M.A., Wanyoko, J.K. and Owuor, P.O. (2013) Variation in Catechin Composition of Popularly Cultivated Tea Clones in East Africa (Kenya). American Journal of Plant Sciences, 4, 628-640. http://dx.doi.org/10.4236/ajps.2013.43081

[41] Kerio, L.C., Wachira, F.N., Wanyoko, J.K. and Rotich, M.K. (2012) Characterization of Anthocyanins in Kenyan Teas: Extraction and Identification. Food Chemistry, 131, 31-38. http://dx.doi.org/10.1016/j.foodchem.2011.08.005

[42] Kilel, E.C., Faraj, A.K., Wanyoko, J.K., Wachira, F.N. and Mwingirwa, V. (2013) Green Tea from Purple Leaf Coloured Tea Clones in Kenya-Their Quality Characteristics. Food Chemistry, 141, 769-775. http://dx.doi.org/10.1016/j.foodchem.2013.03.051 
[43] Ngure, F.M., Wanyoko, J.K., Mahungu, S.M. and Shitandi, A.A. (2009) Catechins Depletion Patterns in Relation to Theaflavin and Thearubigins Formation. Food Chemistry, 115, 8-14. http://dx.doi.org/10.1016/j.foodchem.2008.10.006

[44] Peterson, J., Dwyer, J., Bhagwat, S., Haytowitz, D., Holden, J., Eldridge, A.L., Beecher, G. and Aladesanmi, J. (2005) Major Flavonoids in Dry Tea. Journal of Food Composition and Analysis, 18, 487-501. http://dx.doi.org/10.1016/j.jfca.2004.05.006

[45] Obanda, M., Owuor, P.O. and Taylor, S.J. (1997) Flavanol Composition and Caffeine Content of Green Leaf as Quality Potential Indicators of Kenyan Black Teas. Journal of the Science of Food and Agriculture, 74, 209-215. http://dx.doi.org/10.1002/(SICI)1097-0010(199706)74:2<209::AID-JSFA789>3.0.CO;2-4

[46] Wright, L.P., Mphangwe, N.I.K., Nyirenda, H.E. and Apostolides, Z. (2000) Analysis of Caffeine and Flavan-3-ol Composition in the Fresh Leaf of Camellia sinensis for Predicting the Quality of the Black Tea Produced in Central and Southern Africa. Journal of the Science of Food and Agriculture, 80, 1823-1830. http://dx.doi.org/10.1002/1097-0010(200010)80:13<1823::AID-JSFA702>3.0.CO;2-E

[47] Fernández, P.L., Martín, M.J., González, A.G. and Pablos, F. (2000) HPLC Determination of Catechins and Caffeine in Tea. Differentiation of Green, Black and Instant Teas. Analyst, 125, 421-425. http://dx.doi.org/10.1039/a909219f

[48] Arranz, S., Saura-Calixto, F., Shaha, S. and Kroon, P.A. (2009) High Contents of Nonextractable Polyphenols in Fruits Suggest that Polyphenol Contents of Plant Foods Have Been Underestimated. Journal of Agricultural and Food Chemistry, 57, 7298-7303. http://dx.doi.org/10.1021/jf9016652

[49] Rajaei, M., Barzegar, M. and Sahari, M.A. (2008) Comparison of Antioxidative Effect of Tea and Sesame Seed Oils Extracted by Different Methods. Journal of Agricultural Science and Technology, 10, 345-350.

[50] Shao, P., Liu, Q., Fang, Z. and Sun, P. (2014) Chemical Composition, Thermal Stability and Antioxidant Properties of Tea Seed Oils Obtained by Different Extraction Methods: Supercritical Fluid Extraction Yields the Best Oil Quality. European Journal of Lipid Science and Technology, 117, 355-365. http://dx.doi.org/10.1002/ejlt.201400259

[51] Rajaei, A., Barzegar, M. and Yamini, Y. (2005) Supercritical Fluid Extraction of Tea Seed Oil and Its Comparison with Solvent Extraction. European Food Research and Technology, 220, 401-405. http://dx.doi.org/10.1007/s00217-004-1061-8

[52] Saxena, D.K., Sharma, S.K. and Sambi, S.S. (2011) Comparative Extraction of Cottonseed Oil by $n$-Hexane and Ethanol. ARPN Journal of Engineering and Applied Sciences, 6, 84-89.

[53] Owuor, P.O., Chavanji, A.M. and Munavu, R.M. (1985) Chemical Studies of the Kenyan Tea Seeds. I. Physical and Chemical Characteristics of the Kernel Oil. Tea, 6, 23-28. 